DOI: 10.4322/978-65-89910-16-9-04

\title{
MERCHANDISING COMO ESTRATÉGIA DE PROMOÇÃO DE VENDAS: um estudo realizado em uma loja de roupas femininas
}

\author{
Luano Ferreira Farias ${ }^{17}$ \\ Mauro Leray ${ }^{18}$ \\ Milena Silva Santos ${ }^{19}$ \\ Milena Vieira de Oliveira ${ }^{20}$ \\ Rodrigo Brandão Ferreira ${ }^{21}$
}

17 Discente do curso de Administração da Faculdade Edufor. E-mail: luanoffarias@hotmail.com

${ }^{18}$ Docente da Faculdade Edufor. E-mail: mauro.leray@edufor.edu.br

19 Administradora e especialista em Marketing. E-mail: milenasilvasantos25@gmail.com

${ }^{20}$ Administradora e Mestranda na FUCAPE. E-mail: mileoliveira@ig.com.br ${ }^{21}$ Administrador e Diretor Financeiro da FAPEMA - Fundação de Amparo à Pesquisa e ao Desenvolvimento Tecnológico do Maranhão. E-mail: rodrigorbf84@gmail.com 


\section{RESUMO}

Este artigo é resultado de um estudo sobre o uso das estratégias de merchandising como promoção de vendas em uma loja de roupas femininas objetivando demonstrar se a aplicação dessas pode aumentar o volume de vendas. A pesquisa realizada é descritiva, de natureza aplicada, constitui-se em estudo de caso no qual realizouse uma análise documental por meio de uma abordagem qualitativa. O estudo foi desenvolvido entre agosto e outubro de 2019, no entanto, adquiriu informações do volume de vendas da loja a contar de janeiro de 2019 a outubro de 2019. As estratégias analisadas foram vitrinismo, manequim, cross merchandising e marketing sensorial. Os resultados do estudo apontam que as estratégias elevaram as vendas na loja física. Desta forma, conseguiu-se demonstrar a relevância do merchandising no ponto de venda para chamar a atenção do cliente gerando impulso de compra, permitindo à loja o alcance de melhores resultados.

Palavras-chave: Marketing. Vendas. Merchandising.

\section{ABSTRACT}

This article is the result of a study on the use of merchandising strategies as sales promotion in a women's clothing store in order to demonstrate if applying these strategies can increase sales volume. The research is descriptive, of applied nature, it is a case study whose documentary analysis was performed through a qualitative approach. The study was conducted between August and October 2019, but acquired information on store sales volume from January 2019 to October 2019. The strategies analyzed were window dressing, dummy, cross 
merchandising and sensory marketing. The study results indicate that strategies increased sales at the physical store. In this way, it was possible to demonstrate the relevance of merchandising at the point of sale to attract customer attention, generating buying momentum, allowing the store to obtain better results.

Keywords: Marketing. Sales. Merchandising.

\section{INTRODUÇÃO}

Para acompanhar a evolução do mercado, adaptarse a mudanças é importante. Dessa maneira, adotar estratégias de promoção pode ser uma das formas para que empresas se destaquem em seu segmento. Este artigo analisa a influência do merchandising na promoção de vendas, apresentando embasamento teórico sobre suas estratégias. Tem intuito de descrever se tal recurso pode ou não ajudar a superar a concorrência e promover o produto no ponto de venda (PDV), onde o cliente pode sentir-se atraído em efetuar a compra.

Com os constantes avanços da tecnologia, o cliente tem opção de realizar seus pedidos através de lojas virtuais. Dessa forma, torna-se relevante o uso de técnicas de promoção em lojas físicas para garantir uma 
experiência agradável ao cliente e, com isso, estimular a venda dos produtos ofertados e seu possível retorno. Sendo assim, muitas organizações têm adotado o merchandising com intenção de atrair os clientes ao PDV e incentivar a compra.

As estratégias de merchandising ganham cada vez mais espaço nas lojas de diversos segmentos a partir do momento em que o público-alvo é definido. No ramo de vestuário feminino, empresários investem no planejamento da loja, a começar pela vitrine, que é a primeira impressão que o cliente tem. Além da vitrine, investimentos em iluminação, sinalização, utilização de todos os espaços da loja e marketing sensorial. Tais estratégias de merchandising, podem ser mais um diferencial para destacar a organização diante da concorrência.

De acordo com os aspectos apresentados, essa pesquisa se propõe a responder a seguinte questão: As estratégias de merchandising podem potencializar as vendas em uma loja de roupas femininas? Para resolução deste problema, realizou-se uma análise documental por observação, que incluem as atividades e tarefas de 
merchandising desempenhadas na loja. Para tanto, considerou-se a maneira que elas impactam ou não no volume de vendas.

A pesquisa tem como objetivo avaliar a observância das estratégias de merchandising, bem como suas formas de chamar atenção do cliente no PDV para gerar interesse de compra. Dessa forma, concebe-se uma análise qualitativa a respeito das vendas com a utilização das estratégias que cabem no seguimento retratado. Vale ressaltar que, com o acirramento da concorrência e as mudanças recorrentes no mercado, investir em estratégias para promoção de vendas é importante para subsistência e crescimento da organização.

Neste sentido, torna-se considerável a análise sobre as estratégias do merchandising, para que o cliente tenha uma boa impressão da loja. É relevante destacar que, se utilizado de maneira correta, o merchandising pode trazer um bom retorno por se tratar de uma promoção no PDV, onde o cliente se encontra no presente. Diante da escassez de artigos com essa proposição de problemas e variáveis, o presente artigo pode tornar-se referência para novas pesquisas e outros trabalhos acadêmicos. Com 
isso, poderá somar para o avanço e inovação das estratégias de merchandising para administradores e empreendedores.

\section{REVISÃO BIBLIOGRÁFICA}

Para que o presente artigo atinja seus propósitos, é necessário que se faça uma contextualização acerca das teorias e artigos existentes, cujo propósito será o de dar consistência técnica-científica a este trabalho. Neste sentido, é requerida uma abordagem aos seguintes temas: Marketing; Merchandising; e Vendas no Varejo, que entende ser o caminho para a análise do problema suscitado neste artigo. O objeto deste subtítulo é a contextualização do tema proposto por ele. A construção do texto deverá permitir ao leitor uma compreensão acerca da temática deste item.

\subsection{Marketing}

O marketing consiste em lidar com o mercado em constante transformação. Para entender o marketing, é necessário acompanhar as mudanças recorrentes no 
mercado, como ele tem evoluído ao longo dos anos e estudar o comportamento do novo consumidor. Jovens que optam por um estilo de vida da cidade grande, em sua maioria pertencentes à classe média, com dinheiro para gastar, preferem produtos mais sofisticados. Esses traços fazem desses consumidores um mercado irresistível para os profissionais de marketing (KOTLER, KARTAJAYA, SETIAWAN, 2017, p. 33).

O conceito de marketing se baseia em quatro pilares, sendo eles: a) Mercado-alvo, o qual deve ser definido pela empresa, considerando a inviabilidade de atender a todos os mercados existentes. Nessa perspectiva, é interessante que a organização defina cuidadosamente seu mercado-alvo, para proporcionar melhor atendimento e preparar um programa de marketing sob medida para seu público. b) Necessidade dos consumidores, a empresa deve buscar identificar tais necessidades reais e atendê-las melhor que seus concorrentes. c) Marketing integrado é a união de todos os departamentos da organização para atender os consumidores. d) Rentabilidade proporciona à empresa atingir os objetivos 
e metas financeiras ao atender aos anseios do seu mercado-alvo (LERAY, 2019, p. 42).

O acirramento da concorrência gerou nas organizações a necessidade de comercializar seus produtos de maneira mais eficiente, com isso, pessoas são diariamente expostas às variadas técnicas de marketing. Tais técnicas podem ser constatadas tanto nas ruas por meio de cartazes, placas, letreiros; quando em casa, com propagandas na internet, em programas de televisão e até mesmo com visitas de vendedores e representantes. Tudo isso engloba partes do marketing (LAS CASAS, 2017, p. 1).

Diferente do que muitos pensam, o marketing não é apenas vendas e propagandas, essas constituem apenas a ponta do iceberg do marketing, que é um processo administrativo e social que funciona como uma troca. $\mathrm{O}$ marketing proporciona que a empresa construa fortes relacionamentos lucrativos e de valor com os clientes. Dessa forma, o marketing é relevante para o sucesso das organizações (KOTLER, ARMSTRONG, 2015, p. 4).

O marketing pode ser observado do ponto de vista social e gerencial. No social, pessoas têm suas 
necessidades identificadas e atendidas pela criação da oferta de produtos. No gerencial, um dos objetivos é vender o produto e gerar lucro para a organização (SOUZA, 2016, p. 3). O marketing melhora a qualidade de vida dos clientes, pois oferece soluções adequadas para suprir necessidades. Com isso, pode ser considerado como uma filosofia para a empresa; a imposição dos clientes define seus produtos, serviços, preços, comunicação e distribuição (COBRA, URDAN, 2017, p. 2).

Kotler e Keller (2012, p. 5) explicam que profissionais de marketing são responsáveis pelo gerenciamento da demanda, seja ela negativa, quando o público-alvo evita o produto; inexistente, quando as pessoas desconhecem ou não se interessam pelo produto; latente, quando há uma forte necessidade que não consegue ser satisfeita pelos produtos existentes; demanda em declínio, quando a procura pelo produto está mais baixa; demanda irregular, a qual varia de acordo com a estação do ano; demanda excessiva, mais alta do que a capacidade de atendimento da empresa; e demanda indesejada, a qual se faz por produtos nada saudáveis ou perigosos. Com isso, para atender às demandas os profissionais de marketing 
buscam influenciar o nível, velocidade e composição desses vários estágios da demanda (KOTLER 2005, p. 5).

Viver na era do marketing faz com que as organizações busquem recursos não apenas para serem boas, mas, para que seu público enxergue sua competência ao oferecer seus produtos e serviços. É interessante utilizar recursos de marketing como: a) diferenciação, que mostra a qualidade do produto em comparação ao dos concorrentes; b) convencimento, o qual apresenta a superioridade do produto em comparação a outro; c) relacionamento, para demonstrar ao cliente a importância da empresa; d) oportunidade, acompanha as necessidades dos clientes buscando algo que solucione situações emergentes; e) fixação, associase a marca ao serviço oferecido por ela. Tais recursos são necessários para adaptação e sucesso da organização no mercado (SOUZA, 2017, p. 40).

No Brasil, o marketing não é um fenômeno recente e, mesmo assim, muitas pessoas confundem com propaganda ou com vendas. Entretanto, a crescente concorrência entre as empresas, maior exigência por parte da população brasileira e as importações têm 
estimulado a aceitação do marketing no Brasil. Nos ramos de produtos como: cigarros, alimentos e bebidas, 0 marketing prevalecia. Hoje, este ganha cada vez mais espaço junto ao setor industrial, em atividades agrícolas e pecuárias e em serviços públicos e privados. Até mesmo a política e a religião não ficam fora. Desse modo, percebe-se a expansão do marketing no Brasil (COBRA, URDAN, 2017, p. 11).

Garcia (2015, p.11) explica que, para definir, organizar e planejar os objetivos do setor de marketing, é necessário o uso dos 4 P’s de Mccarty, os quais têm o objetivo de compreender e realizar os desejos dos consumidores. Os 4P's são: a) Produto, que é a primeira decisão da empresa, ela deve saber o que ofertará para seu público; b) Preço, descreve quanto o cliente irá pagar e de que forma ele fará esse pagamento; c) Promoção, responsável pela divulgação do produto; e d) Praça, que é o PDV (ponto de venda), envolve toda distribuição do produto, considerando-se como e quando o produto chegará ao local definido. O PDV é o local onde são aplicadas as estratégias de merchandising que veremos a seguir. 


\subsection{Merchandising}

O merchandising é uma ferramenta completa, pois proporciona o acompanhamento do produto em sua adequação no PDV, ciclo de vida e desempenho; com finalidade de prepará-los para atrair a atenção do consumidor gerando impulso de compra. Mediante um planejamento e aplicação das técnicas de merchandising, o gestor tem possibilidade de prever a distribuição e aceitação do público referente a determinado produto ou serviço que está em exposição no PDV. Com isso, o uso do merchandising pode se tornar um diferencial competitivo para que a empresa ganhe destaque entre os concorrentes (MATTOS, 2015, p. 3).

Ladeira e Santini (2018, p. 8) descrevem que, no varejo, o uso do merchandising se refere a ações que objetivam situar consciente ou inconscientemente a identidade da marca na mente do cliente através de experiências que os mesmos podem ter no PDV. Em uma loja de varejo feminino, tais experiências podem ser motivadas através de estratégias como: vitrinismo, crossmerchandising, marketing sensorial, layout dos produtos, 
MERCHANDISING COMO ESTRATÉGIA DE PROMOÇÃO DE VENDAS: Um estudo realizado em uma loja de roupas femininas

iluminação do ambiente, promoções, disposição espacial das pessoas, entre outras.

Figura 1 - Merchandising

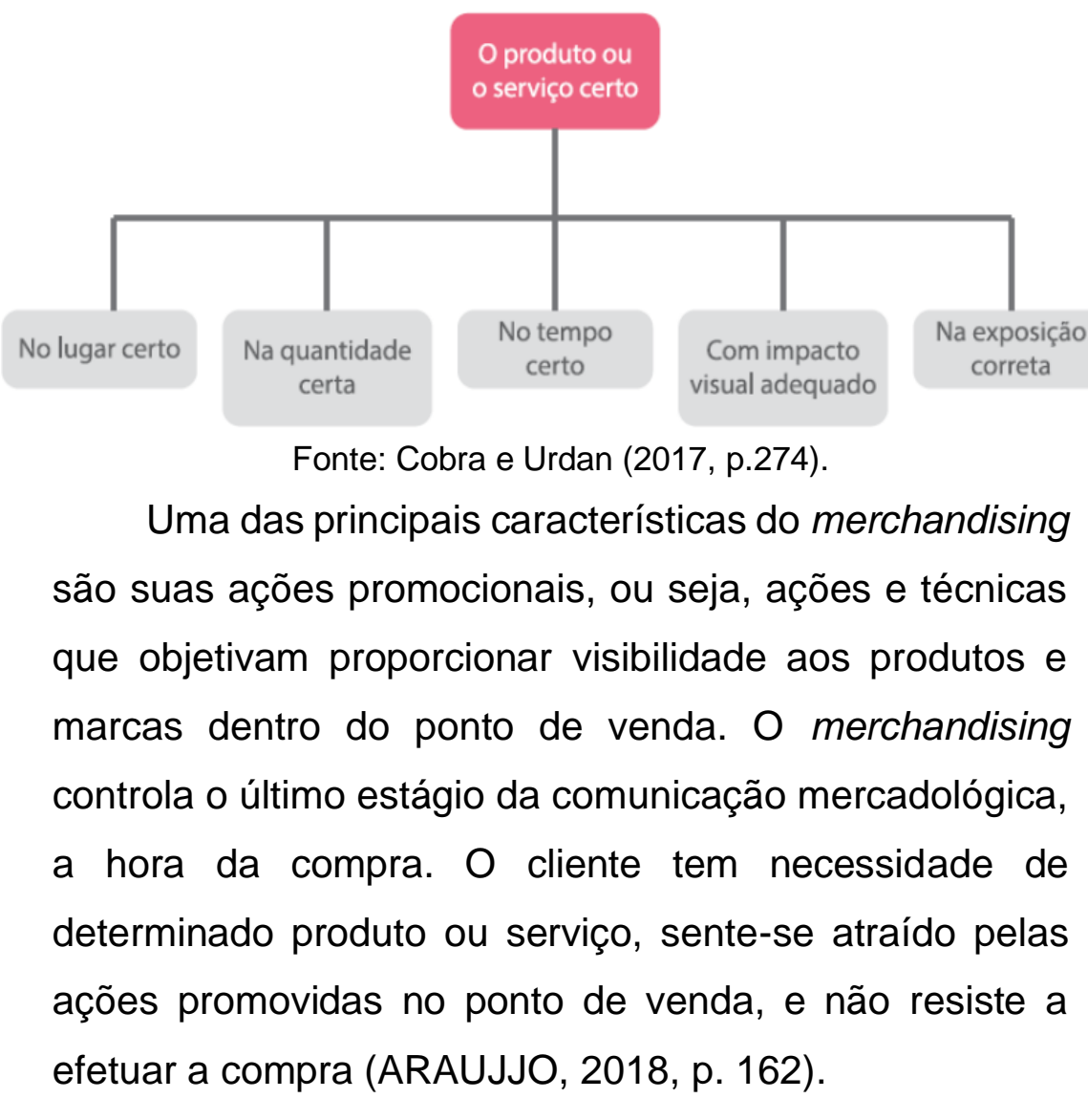

Cobra e Urdan (2017, p. 278) discorrem que, no merchandising, é levado em consideração o lugar certo para oferecer o produto ou serviço. Os gestores devem 
planejar onde o produto será ofertado. É relevante levar em consideração aspectos como: a) Área mercadológica, que é o raio geográfico onde o produto pode ser colocado à venda; b) Zonas mercadológicas, onde especifica-se os limites geográficos, pessoas e seus modos de vida; c) População, o merchandising geográfico leva em consideração o número de pessoas por sexo, classe socioeconômica, faixa etária; d) Custo mercadológico, o gestor deve analisar se o preço do produto pode cobrir os custos mercadológicos: promoção, propaganda, distribuição, merchandising, venda pessoal e etc. É evidente que, quanto mais agressiva for à concorrência, maior será o custo de marketing.

O Planejamento da vitrine faz parte das estratégias de merchandising, e se faz importante para a loja quando se trata de captar o cliente. Ao avistar uma vitrine atrativa, o consumidor projeta sua própria imagem usando o produto ofertado. Com isso, o vitrinismo pode ser uma das ações de menor investimento e maior atratividade para o ponto de venda, além de auxiliar na divulgação do produto, pois, quando bem exposto, gera maior interesse, 
com poder de atrair o cliente para a loja (MATTOS, 2015, p. 9).

Araújo (2018, p. 14) descreve o vitrinismo como a venda através do olhar. Ao andar por ruas ou shoppings, é natural encontrar pessoas paradas para ver a mercadoria do outro lado do vidro. Observar pela vitrine é agradável, é uma mídia de baixo custo e retorno rápido, um convite para o cliente. Uma vitrine bem elaborada é responsável por $70 \%$ das vendas. A vitrine vende bem mais que o produto, pois transmite conceitos, engloba elementos como organização, limpeza, iluminação e disposição das peças, é possível transmitir ao cliente um resumo da loja (ARAUJJO, 2018, p. 14).

A vitrine é o cartão de visita; por ser o primeiro ponto de observação, seu objetivo principal é convidar o cliente para entrar na loja. O tempo entre o cliente olhar a vitrine e decidir entrar na loja é muito curto, por isso a vitrine deve ser bem planejada. A visualização de um produto bem exposto consegue convencer o consumidor da sua qualidade, além de transmitir que vale entrar para se certificar de que o mesmo vai ao encontro de seus 
desejos, ainda que não seja necessário adquirir o produto no momento (ALVES, 2015, p. 5).

Além de uma vitrine organizada e atrativa, para superar a forte concorrência, a empresa pode apostar no marketing sensorial. Este leva o cliente a obter uma ligação com a marca, pois é desafiante para as empresas fixarem seus produtos na mente do consumidor. Com isso, a utilização do marketing sensorial coloca os cinco sentidos visão, audição, paladar, tato e olfato no centro da estratégia e da tática de marketing. Tais sentidos proporcionam ao consumidor três vantagens destacadas a seguir: a) Criação de identidade através do consumo de marcas e experiências; b) Autorrealização por meio da qualidade de vida e bem-estar; c) Experiências sensoriais propriamente ditas ao longo da participação do consumidor como ator sensível, ativo e criativo nessas experiências. Produtos ou serviços, a imagem de uma marca depende das experiências sensoriais notadas pelos clientes (MELO, BRITO, 2014, p. 70).

Outra estratégia relevante para potencializar as vendas é o Cross Merchandising que, por sua vez, é responsável por correlacionar produtos que tem relação 
entre si e destacá-los dos demais no ponto de venda. Combinar os produtos não gera custo extra e pode aumentar as vendas, pois o cliente pode ter interesse em apenas um dos produtos, mas as combinações geram impulso de compra e o consumidor sente necessidade de aderir aos produtos cruzados, pois um faz referência ao outro. (ARAUJJO, 2018, p. 202).

Cobra e Urdan (2016 p. 274) descrevem que, por diversas razões, o uso do merchandising é relevante para o desenvolvimento da organização, pois há muita compra por impulso; quando presentes no PDV, clientes sentem interesse por diversos produtos ou serviços. Assim, com o uso das estratégias de merchandising, a empresa poderá destacar o produto entre tantos em exposição, girar o estoque com mais rapidez e facilidade, e comunicar no PDV as diversas vantagens do produto para seu público-alvo. Com isso, faz-se necessário o reconhecimento de que as estratégias e ações de merchandising são elaboradas e planejadas para elevar e potencializar de forma precisa as vendas no varejo que abordaremos a seguir. 


\subsection{Vendas e Varejo}

No ano de 2015, o Brasil foi afetado por uma intensa crise financeira. Com isso, diversos setores da economia brasileira passaram por transformações, incluindo o setor varejista, o que influenciou diretamente no processo de compra do consumidor. Em razão disso, as empresas investiram na promoção de vendas, sobretudo, no composto do marketing como ferramenta decisiva para superar seus concorrentes, fidelizar clientes e promover a marca (SILVA, et. al. 2016, p 96).

O varejo integra as atividades envolvidas na venda de produtos ou serviços diretamente aos compradores finais para uso pessoal. Lojas varejistas assumem um papel relevante para que a marca seja conhecida. $40 \%$ dos consumidores decidem comprar quando estão presentes no ponto de venda ou próximo. Dessa forma, varejistas alcançam consumidores em importantes momentos da verdade e influenciam suas ações ao gerar interesse de compra no PDV (KOTLER, ARMSTRONG, 2015, p. 412).

Cada cliente tem seu ponto de vista, logo, não são iguais. Dessa forma, expressam suas diferenças de 
diversas maneiras. Assim, as organizações devem buscar satisfazer às necessidades do seu público, funcionais e emocionais. As pessoas são fortalecidas por inúmeros motivos e necessidades. Maslow identificou cinco necessidades comuns de todas as pessoas, são elas; fisiológicas, segurança, afeto, estima e autorrealização. Com isso, organizações buscam vender produtos e serviços que satisfaçam tais necessidades do seu públicoalvo (COBRA, URDAN, 2017, p. 19).

Existem diferentes subgrupos de clientes: a) Consumidor eventual, que compra quando é necessário, tem suas compras planejadas e conseguem bons descontos; b) Consumidor impulsivo, que não resiste a promoções e lançamentos; c) Consumidor compulsivo, busca suprir às suas necessidades emocionais através da compra; d) Clássicos, estilo conservador, seus hábitos são ir ao trabalho e vida social; e) Modernos, buscam por peças únicas; f) Exuberantes, preferência por peças chamativas, costumam ir a festas e comemorações; g) Poderosos, em sua maioria mulheres que optam por peças justas e decotadas; h) Originais, criadores de tendências, optam por marcas desconhecidas. Diante 
disso, identificar o perfil do consumidor atual requer atenção por parte dos empresários pois poderá trazer inúmeros benefícios para a empresa (ANDRADE et. al. 2015, p. 7).

Além de ferramentas de promoções de vendas, os gerentes de marketing devem definir o gerenciamento da força de vendas como a análise, implementação e controle das atividades. Não basta apenas investir em promoções, o atendimento também é relevante para incentivar o cliente a adquirir o produto ou serviço ofertado pela organização. Deve-se levar em consideração recrutamento, seleção, treinamento, remuneração, supervisão e avaliação dos vendedores da empresa. (KOTLER, ARMSTRONG, 2015, p. 516).

Ao tratar de vendas, é interessante estabelecer objetivos e metas, pois os mesmos favorecem 0 planejamento, organização e controle; além de beneficiar a eficiência e eficácia ao tratar dos recursos humanos, físicos e financeiros. Dessa forma, objetivos e metas bem definidos contribuem para o sucesso da organização. Não basta apenas falar à equipe de vendas que esta deve ter um bom desempenho. É interessante que o gestor 
demonstre de forma concreta e tangível, mediante metas que certificam o volume de vendas, valor monetário, número de clientes ou de demonstrações de produtos a serem realizados no mês. Assim, com esse padrão de medidas, o vendedor saberá julgar o quanto seu desempenho é ou não satisfatório (COBRA, URDAN, 2017, p. 340).

Promover a marca, potencializar as vendas e fidelizar clientes diante de um mercado competitivo não é simples. Dessa forma, as organizações buscam satisfazer às necessidades do consumidor e proporcionar aos mesmos várias promoções. Se adaptar a um mercado onde o público tem muito acesso à informação e pouco tempo disponível não é uma tarefa fácil. Dessa maneira, a organização deve buscar alternativas que conquistem os clientes, não apenas pelo bolso. Com ações criativas e inovadoras, bom uso das ferramentas de promoção e dedicação por parte dos vendedores, a organização poderá manter bom relacionamento com seus clientes por longo prazo (SILVA, 2016, p. 105).

\section{PROCEDIMENTOS METODOLÓGICOS}


MERCHANDISING COMO ESTRATÉGIA DE PROMOÇÃO DE VENDAS: Um estudo realizado em uma loja de roupas femininas

Esta pesquisa se desenvolve a partir do pressuposto de como as estratégias de merchandising podem influenciar as vendas, levando em consideração uma loja de roupas femininas. A pesquisa realizada é descritiva, de natureza aplicada, constitui-se em um estudo de caso no qual realizou-se uma análise documental, logo, sua abordagem é qualitativa. Vergara (2016, p. 44) descreve que "a pesquisa aplicada é fundamentalmente motivada pela necessidade de resolver problemas concretos, mais imediatos, ou não. Tem, portanto, finalidade prática".

Quanto aos objetivos, a pesquisa é descritiva, pois foi feita uma descrição da situação da empresa. As pesquisas descritivas intentam analisar as variáveis bem como criar relações entre elas e, logo em seguida, levantar hipóteses que possam explicar essas relações. Dessa forma, parte de um problema existente na organização e, mediante a coleta de dados, é feita uma análise para encontrar soluções para determinado problema (BERTUCCI, 2015, p. 50).

Nos procedimentos, realizou-se um estudo de caso, o qual é detalhado, utilizando-se de métodos 
diferenciados de coleta de dados, restrito a uma ou poucas unidades, podendo ser feito com pessoas, famílias, produtos, empresas, entre outros (VERGARA 2016, p. 44). Neste artigo, o estudo de caso é realizado em uma empresa (loja de roupas femininas) e com as pessoas (gestores) responsáveis pela mesma.

Os diversos estudos e pesquisas podem ser conduzidos com abordagens qualitativas, quantitativas ou com as duas ao mesmo tempo denominadas de mistas. Para a realização da pesquisa, a abordagem adequada é a qualitativa, pois tem o ambiente como a fonte de coleta de dados e o pesquisador como instrumento relevante para realizar a análise e descrever os resultados (ALMEIDA, 2014, p. 26).

\section{ANÁLISE DO ESTUDO DE CASO}

O presente estudo é divido em três partes, sendo a primeira delas a apresentação da empresa, histórico e forma de trabalho. Logo após, na segunda parte, apresentam-se as estratégias de merchandising utilizadas pela loja de segmento e a forma que essas estratégias são 
aplicadas na mesma. Na parte três do estudo é feita a análise dos resultados em comparação ao referencial teórico com o intuito de resolver o problema levantado a princípio, o qual questiona se as estratégias de merchandising podem ou não potencializar as vendas em uma loja de roupas femininas.

\subsection{Histórico}

A história da Ana's Fernandes teve início em 2015, quando a estudante visionária Ana Carolina Fernandes decidiu criar sua marca para apresentar novidades e dicas aos seus consumidores com a motivação de expandir o mercado de vestuário em São Luís - MA. A Ana's Fernandes é uma empresa multimarcas, lançada inicialmente de forma virtual através das redes sociais Facebook e Instagram. A empresa ganhou mercado e fechou parceria com grandes marcas da moda feminina, como Enna, Sly Wear e Myft. Com comprometimento e dedicação, a Ana's Fernandes conseguiu fidelizar clientes e ganhar uma diversidade de seguidores nas redes sociais. Dado ao sucesso do empreendimento, três anos depois inaugurou a loja física para melhor atender seu 
público, oferecendo uma nova opção, a compra presencial.

Em sua missão, a Ana's Fernandes preza por oferecer a mulheres "vestimentas especiais e fazer com que a experiência de escolha seja a mais prazerosa e agradável possível, prestando o suporte necessário para que o resultado final atinja a satisfação desejada de todos os seus clientes". A Visão da Ana's Fernandes é "ser a maior rede varejista de venda e locação de trajes especiais para momentos de grande importância na vida de seus consumidores em todo o Brasil". Em seus valores, a empresa preza pela responsabilidade, comprometimento, ética, respeito e excelência.

A Ana's Fernandes está se preparando para expandir o negócio e abrir mais duas lojas físicas, o que proporcionará a seus clientes mais opções de acesso aos produtos ofertados. Atualmente a Ana's Fernandes tem sua loja física localizada na Ponta do Farol, Avenida dos Holandeses, em São Luís - MA. Os produtos ofertados pela loja são blusas, saias, shorts, vestidos, macacões, bolsas, carteiras, sapatos, cintos e acessórios. Opções 
essenciais para vestir com qualidade e elegância seu público.

Atualmente a Ana's Fernandes é uma loja exclusivamente de vestuário feminino. A loja oferece uma estrutura confortável, atende o público também nas redes sociais e faz entregas em todo o Brasil. Em datas comemorativas, faz parcerias com outras empresas para presentear suas clientes. No lançamento de coleções, a Ana's Fernandes promove ações como coquetéis para receber seu público. Em tempos de renovação de estoques, promove liquidações das peças remanescestes da coleção anterior com até $70 \%$ de desconto.

\subsection{Estratégias de Merchandising que a loja utiliza}

Neste momento serão pontuadas as estratégias de merchandising utilizadas pela empresa para potencializar as vendas de acordo com os métodos estabelecidos. Tais métodos foram coleta de dados sobre a caracterização da empresa, análise documental do volume de vendas, observação e registro de fotos. Através dos mesmos, pode-se concluir que a empresa utiliza estratégias que serão elencadas a seguir. 


\subsubsection{Vitrinismo}

A vitrine da Ana's Fernandes é uma vitrine aberta que possibilita a visualização de dentro da loja pelo cliente, a mesma é exposta de forma constitucional, pois transmite conceito onde são exibidas coleções, evidenciando um produto novo que chegou, lançamento de alguma linha, um tema da coleção e até mesmo para evidenciar datas comemorativas. É composta de três manequins que destacam a coleção. A iluminação da vitrine é feita por cinco lâmpadas Led que focam nos manequins expostos, melhorando a visibilidade das peças apresentadas.

As peças dispostas na vitrine são trocadas diariamente e a organização é de responsabilidade da proprietária Ana Carolina Fernandes, que já participou de um curso sobre vitrinismo, para aprender mais sobre a exposição. Ao organizar as peças que serão expostas na vitrine, ela preza pela harmonia dos tons usando geralmente uma mesma estampa ou cores próximas. No vidro que compõe a vitrine estão colados adesivos com a logomarca da Ana's Fernandes e das marcas que a mesma oferta. 
MERCHANDISING COMO ESTRATÉGIA DE PROMOÇÃO DE VENDAS: um estudo realizado em uma loja de roupas femininas

Figura 2 - Vitrine da loja

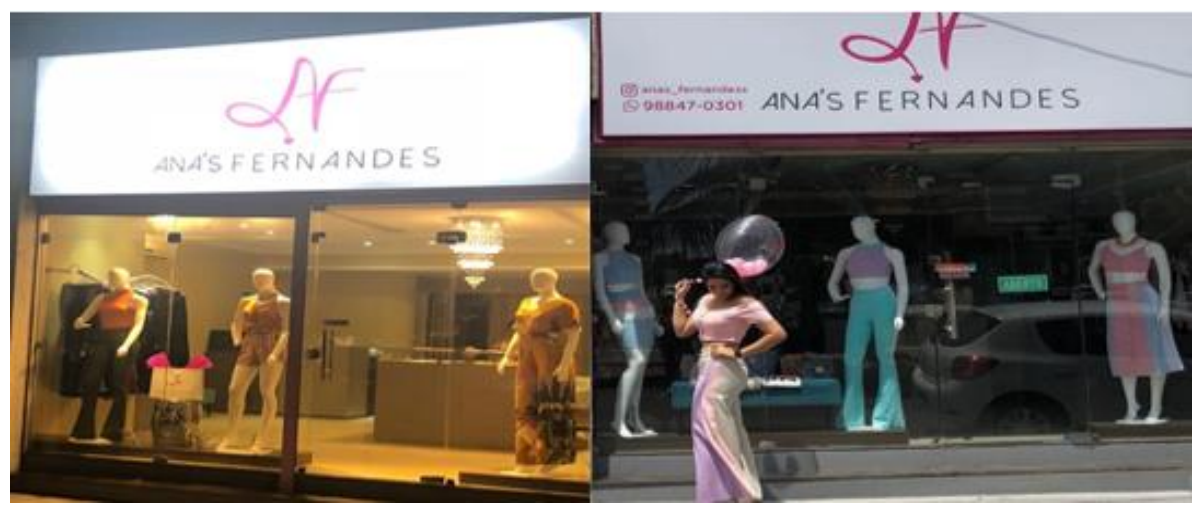

Fonte: Dados da pesquisa, 2019.

4.2.2 Marketing Sensorial

A Ana's Fernandes utiliza apenas uma estratégia de marketing sensorial que é a audição. As músicas são selecionadas pela Ana Carolina, que as escolhe pensando em seu público-alvo. A playlist é alterada duas vezes ao mês, e a aceitação das músicas por parte das clientes é notada a partir do momento em que as mesmas começam a interagir com a música, cantando e elogiando ao ouvi-las, há clientes que, mesmo após realizar suas compras, esperam a música terminar para sair do estabelecimento.

4.2.3 Manequim 
MERCHANDISING COMO ESTRATÉGIA DE PROMOÇÃO DE VENDAS: Um estudo realizado em uma loja de roupas femininas

Na Ana's Fernandes são utilizados cinco manequins, três deles compõem a vitrine, um deles é utilizado para exibir os colares e o quinto manequim compõe a vitrine em alguns momentos, e também é usado perto das araras evidenciando algum produto que deve ser destacado. Os manequins utilizados na vitrine são padronizados em uma mesma cor, os quais podem ser utilizados para expor, além das roupas, acessórios, sapatos e bolsas levando a outra estratégia, o cross merchandising, que abordaremos a seguir.

\section{Figura 3 - Manequim}
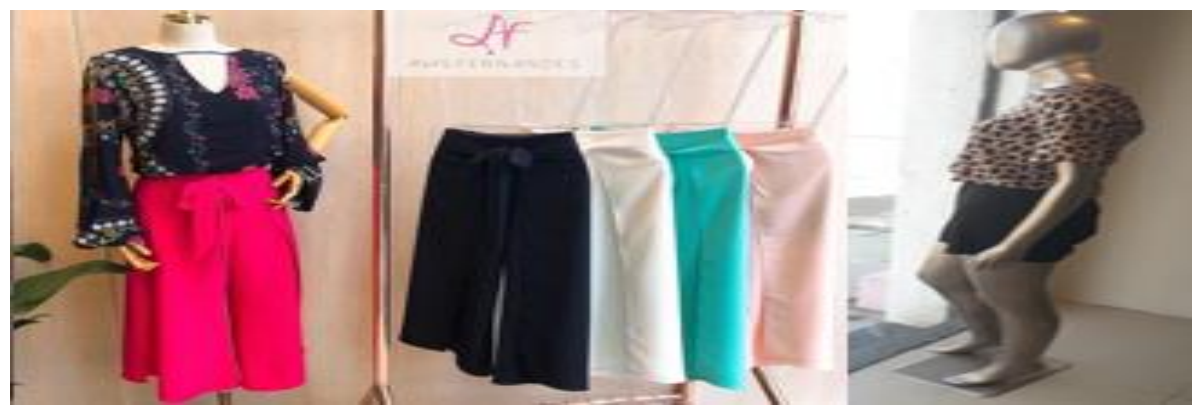

Fonte: Dados da pesquisa, 2019.

4.2.4 Cross Merchandising

A Ana's Fernandes utiliza cross merchandising nos manequins que compõem a vitrine e nas araras expondo as peças de forma diferenciada, cruzando as roupas com os demais produtos ofertados na loja como: cinto, colar, 
MERCHANDISING COMO ESTRATÉGIA DE PROMOÇÃO DE VENDAS: um Estudo realizado em uma loja de roupas femininas

calçado e bolsa. Esta estratégia oferece ao cliente uma opção de look completo, o que auxilia na escolha da peça. Algumas peças não tiveram boa aceitação a princípio, mas, após as combinações, as clientes visualizaram melhor e efetuaram a compra. Há clientes que vão à loja com o intuito de comprar apenas uma peça específica e, ao serem influenciados pelas combinações, acabam levando o look inteiro.

Figura 4 - Peças combinadas

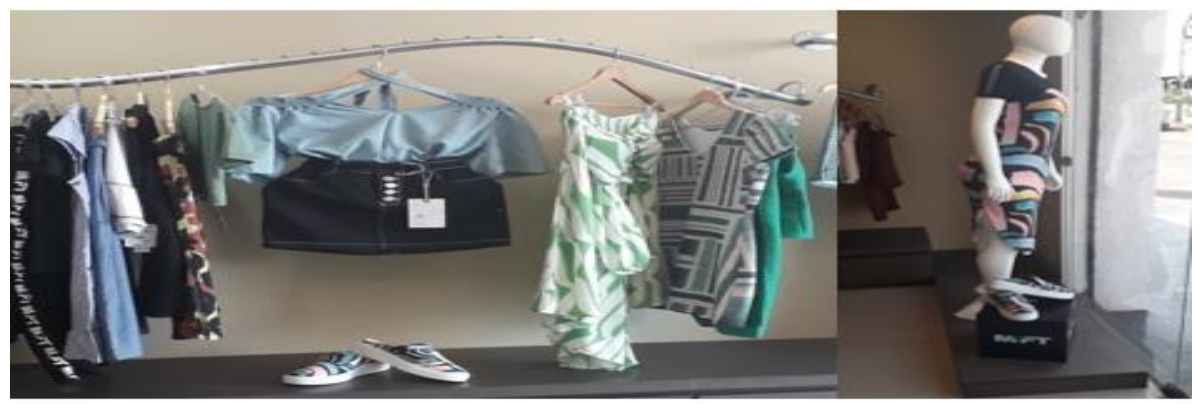

Fonte: Dados da pesquisa, 2019.

4.2.5 Volume de Vendas

A tabela 1 representa o volume de vendas das peças antes e depois de serem expostas na vitrine. Para tal, foram selecionados 10 modelos em um período de 10 meses, cada modelo representando um mês a contar de janeiro de 2019 até outubro de 2019. O volume será apresentado em porcentagem, e vale ressaltar que os 
MERCHANDISING COMO ESTRATÉGIA DE PROMOÇÃO DE VENDAS: Um estudo realizado em uma loja de roupas femininas

modelos foram expostos nas araras da loja e no Instagram, ferramenta de divulgação da empresa. Mas, para constatação da eficiência do vitrinismo, será pontuado como venda após a estratégia apenas os modelos vendidos ao estarem expostos na vitrine da loja física.

Tabela 1 - Vitrinismo

\begin{tabular}{|c|c|c|c|}
\hline MÉS/ANO & MODELO & ANTES & DEPOIS \\
\hline Jan de 2019 & Cropped borboleta & $50 \%$ & $50 \%$ \\
\hline Fev de 2019 & Vestido mid canelado & $16,66 \%$ & $83,33 \%$ \\
\hline Mar de 2019 & Vestido dress & $0 \%$ & $100 \%$ \\
\hline Abr de 2019 & Macacão longo & $50 \%$ & $50 \%$ \\
\hline Mai de 2019 & Blazer & $80 \%$ & $30 \%$ \\
\hline Jun de 2019 & Conjunto Mid & $0 \%$ & $100 \%$ \\
\hline Jul de 2019 & Cropped ciganinha & $70 \%$ & $30 \%$ \\
\hline Ago de 2019 & Vestido Poar & $0 \%$ & $100 \%$ \\
\hline Set de 2019 & Vestido tranças & $40 \%$ & $60 \%$ \\
\hline Out de 2019 & Vestido retrô & $50 \%$ & $50 \%$ \\
\hline
\end{tabular}

Fonte: Dados da pesquisa, 2019.

Através dos dados apresentados na tabela, pode-se confirmar que o uso da vitrine é um dos fatores cruciais para as vendas na loja, pois alguns produtos, a exemplo dos meses de julho e agosto, só foram vendidos após a exposição na vitrine. Nesse contexto, faz-se uma confirmação do referencial teórico, com base na abordagem de Araújo (2018), ao dizer que "uma vitrine 
bem elaborada é responsável por $70 \%$ das vendas" e que a vitrine transmite conceitos e através da disposição das peças é possível transmitir ao cliente um resumo da loja. Confirma-se, também, o que foi abordado por Mattos (2015), que vitrinismo, além de auxiliar na divulgação dos produtos, gera maior interesse com poder de atrair 0 cliente para o ponto de venda. Seguindo o exemplo da tabela anterior, neste momento, serão apresentados na tabela 2, dez modelos expostos em manequim a partir do mês de janeiro de 2019 até outubro de 2019, totalizando dez meses sendo um modelo para cada mês.

Tabela 2 - Manequim

\begin{tabular}{|c|c|c|c|}
\hline MÊS/ANO & MODELO & ANTES & DEPOIS \\
\hline Jan de 2019 & Vestido longo & $50 \%$ & $50 \%$ \\
\hline Fev de 2019 & Conjunto saia e cropped & $16,66 \%$ & $83,33 \%$ \\
\hline Mar de 2019 & Calça e blusa social & $0 \%$ & $100 \%$ \\
\hline Abr de 2019 & Conjunto & $50 \%$ & $50 \%$ \\
\hline Mai de 2019 & Vestido xadrez & $80 \%$ & $30 \%$ \\
\hline Jun de 2019 & Saia news & $0 \%$ & $100 \%$ \\
\hline Jul de 2019 & Blazer e calça & $70 \%$ & $30 \%$ \\
\hline Ago de 2019 & Saia envelope e cropped & $0 \%$ & $100 \%$ \\
\hline Set de 2019 & Blusinha com ombreira & $40 \%$ & $60 \%$ \\
\hline Out de 2019 & Vestido poar & $50 \%$ & $50 \%$ \\
\hline
\end{tabular}

Fonte: Dados da pesquisa, 2019.

O merchandising é uma ferramenta que tem a finalidade de preparar o produto para atrair a atenção do 
MERCHANDISING COMO ESTRATÉGIA DE PROMOÇÃO DE VENDAS: Um Estudo realizado em uma loja de roupas femininas

consumidor, dessa forma, os modelos que são expostos nos manequins conseguem não só chamar atenção do cliente no PDV como também gerar impulso de compra. Através dos dados apresentados na tabela pode-se concluir que em alguns meses, partir do momento em que a peça foi destacada as vendas aumentaram, há produtos que foram vendidos apenas depois da exposição no manequim, o que demonstra a eficácia da estratégia.

Tabela 3 - Cross Merchandising

\begin{tabular}{|c|c|c|c|}
\hline MÊS/ANO & MODELO & ANTES & DEPOIS \\
\hline Jan de 2019 & Saia Neon + Cropped & $50 \%$ & $50 \%$ \\
\hline Fev de 2019 & Cropped + Saia Animal & $16,66 \%$ & $83,33 \%$ \\
\hline Mar de 2019 & Calça + Blusa + Cinto & $0 \%$ & $100 \%$ \\
\hline Abr de 2019 & Cropped + Saia + Carteira & $50 \%$ & $50 \%$ \\
\hline Mai de 2019 & Cropped + Calça + Bolsa & $80 \%$ & $30 \%$ \\
\hline Jun de 2019 & Blazer + Cinto & $0 \%$ & $100 \%$ \\
\hline Jul de 2019 & Saia + Cropped + Colar & $70 \%$ & $30 \%$ \\
\hline Ago de 2019 & Calça + Cropped + Cinto & $0 \%$ & $100 \%$ \\
\hline Set de 2019 & Saia poar + Blusa + Tênis & $40 \%$ & $60 \%$ \\
\hline Out de 2019 & Saia + Cropped + Colar & $50 \%$ & $50 \%$ \\
\hline
\end{tabular}

Fonte: Dados da pesquisa, 2019.

$\mathrm{Na}$ tabela 3 segue a representação de 10 modelos cruzados no cross merchandising. Seguindo o mesmo raciocínio das tabelas anteriores, pode-se observar através dos dados da tabela que o cross merchandising na Ana's Fernandes tem aceitação significante por parte 
dos consumidores, assim, conclui-se que os compradores estão buscando praticidade na escolha de seus produtos. Ter um look trabalhado e completo à disposição é vantajoso ao consumidor que não precisa gastar tempo e energia para fazer suas combinações. Há clientes que vão à loja para comprar apenas uma peça específica e, ao visualizar as combinações, acabam levando o look completo. Uma das vantagens do cross merchandising é que para usá-lo não há elevação do custo, pois basta combinar os produtos já ofertados.

\section{CONSIDERAÇÕES FINAIS}

Com as constantes mudanças recorrentes no mercado, a adaptação é essencial para a sobrevivência da empresa. Dessa forma, o uso de técnicas para promover os produtos e chamar a atenção do cliente para a loja é imprescindível. O presente artigo se propôs a responder se as estratégias de merchandising podem ou não potencializar as vendas. Para comprovar a teoria apresentada no referencial teórico, foi feito um estudo de caso com a loja de roupas femininas Ana's Fernandes, 
que utiliza algumas das estratégias, como: vitrinismo, manequim, cross merchandising e marketing sensorial, especificamente a utilização da audição. O estudo foi desenvolvido através de uma análise documental do volume de vendas que resultou na eficácia das estratégias cuja contribuição para o aumento das vendas na loja foi comprovada nas tabelas.

O vitrinismo mostrou-se essencial para convidar o consumidor a adentrar no PDV. É importante que a vitrine seja bem planejada, levando em consideração o públicoalvo, prezando pela organização, iluminação e utilização de ponto focal onde o público tem melhor acesso de visão ao produto ofertado. Uma vitrine mal planejada pode contribuir para que a loja passe despercebida e, consequentemente, haja redução de vendas.

A estratégia de manequim é interessante para destaque do produto. No estudo, foram apresentados modelos em que todas as peças foram vendidas após a exposição nos manequins. A partir do momento em que a roupa ganha destaque no manequim, os clientes têm uma visão diferenciada de como a mesma pode ficar no corpo humano. As diversas formas de manequins melhoram a 
visualização das peças, conseguem chamar atenção e gerar impulso de compra.

O cross merchandising mostrou-se uma estratégia essencial, pois, quanto menos tempo e energia gastos para escolher as peças no ponto de venda, mais satisfeito o cliente se sentirá. Na Ana's Fernandes, algumas peças não chamavam atenção até serem conjugadas com outras semelhantes e destacadas no PDV, o que gerou no consumidor lembrança e necessidade de adquirir as combinações, o que motivou a compra de mais de um produto. A exemplo, destacam-se as roupas cruzadas com os demais produtos ofertados na loja, como bolsa e sapato, apresentados na tabela 3.

Por fim, o uso do sentido audição através das músicas selecionadas de acordo com a preferência do público contribuiu para permanência e interação dos clientes no PDV, gerando maior possibilidade de venda, pois, quanto mais à vontade o comprador se sente, maior a possibilidade de compra. Vale ressaltar que não é qualquer música aleatória que deve tocar na loja, deve ser feita uma análise do gosto musical do público-alvo. Da mesma forma que a música auxilia na permanência e 
interação dos clientes, ela pode afastar os consumidores da loja ou gerar indisposição na hora da compra.

No entanto, nem sempre as estratégias de merchandising contribuem para elevar o volume de vendas. Algumas estratégias se tornam ineficazes quando utilizadas da maneira inadequada. A exemplo, pode-se citar o vitrinismo: uma vitrine mal planejada poderá afastar o cliente do PDV e até mesmo contribuir para que a loja passe despercebida. Consequentemente, haverá redução no volume de vendas da empresa.

Vale ressaltar, ainda, que há estratégias que se destacam mais, tanto bibliograficamente quanto na presente avaliação feita através de observação e dos dados apresentados pela loja. Como exemplo pode-se citar o cross merchandising, onde a associação dos produtos gera impulso de compra, pois há clientes que a princípio comprariam apenas uma peça e, ao atentarem para as combinações expostas, levam o look inteiro.

A partir desse entendimento, pode-se responder 0 problema levantado no início desse artigo, demonstrando que as estratégias de merchandising podem e são relevantes para potencializar as vendas em uma loja de 
roupas femininas. Ao comparar o volume de vendas na loja física com as vendas feitas nas redes sociais de forma virtual, percebe-se a vantagem que as estratégias geram para potencializar as vendas. Um produto bem exposto chama a atenção do público e gera impulso de compra, dessa maneira, pode-se defender que vale investir nas estratégias de merchandising como diferencial competitivo. 


\section{REFERÊNCIAS}

ANDRADE, Robson Braga. Design do varejo da moda. Serviço brasileiro de apoio a micro e pequenas empresas. 2015. 91p.

ALMEIDA, Mario. Elaboração de projeto, tcc, Dissertação e tese: uma abordagem simples, prática e objetiva. 2.ed. São Paulo: Atlas, 2014. 96p.

ALVES, Luis. Curso Básico de Vitrinismo Aplicado ao textil e á Moda. Editora: Luis Miguel Tavares Alves, fevereiro, 2015. 180p.

ARAUJO, Walter. Visual Merchandising. Clube dos Autores (managed). Independently published, 2018. 223p. BERTUCCI, Janete. Metodologia básica para elaboração de trabalhos de conclusão de cursos (TCC): ênfase na elaboração de TCC de pós-graduação Lato Sensu. 1.ed7 reimpr.- São Paulo: Atlas, 2015.

COBRA, marcos, URDAN, André. Marketing Básico. $5^{\circ}$ edição. Atlas Ltda, 2017. 337p.

GARCIA, Janaina. Marketing de serviços e de varejo. São Paulo: Pearson Education do Brasil, 2015. 
KOTLER, Philip, ARMSTRONG, Gary. Princípios de Marketing. 15. ed. São Paulo: Pearson education, 2015. 780p.

KOTLER, Philip, KARTAJAYA, Hermawan, SETIAWAN, Iwan. Marketing 4.0. EMT editores LTDA. 2017, 257 p. KOTLER, Phillip, KELLER, kevin. Administração de marketing.14. ed. São Paulo: Pearson Education do Brasil, 2012. 768p.

LADEIRA, Wagner, SANTINI, Fernando. Merchandising e promoção de vendas. São Paulo: Atlas, 2018.

LAS CASAS, Alexandre. Marketing: conceito, exercícios, casos. 9.ed. São Paulo: Atlas, 2017. 376p.

LERAY, Mauro. Marketing Descomplicado: introdução a administração de marketing. 2.ed. - Ananideua: Itacaiúnas, 2019. 213p.

MATTOS, Gabriela Ramos. Técnicas de Merchandising. São Paulo: Unisalesiano, 2015. 10p.

MELLO, Carlos, BRITO, Lencast. Novos horizontes do Marketing. Leya, 2014. 275p.

SOUZA, Ovanildo. Trade Marketing. São Paulo: Pearson Education do Brasil, 2016. 133p. 
SOUZA, Thamires Cardoso, Marketing- Mix de Marketing e fidelização. $9^{\circ}$.ed. Revista Gestão em Foco, 2017. 43 p. SILVA, Diego Ferreira. Promoção de vendas: uma ferramenta estratégica para a fidelização de clientes em tempos de crise. Revista Interdisciplinar do pensamento científico. $\mathrm{n}^{\circ} 1$ volume 2 , art $\mathrm{n}^{\circ} 08$. Janeiro/ Junho 2016. p.96- 277.

VERGARA, Sylvia. Projetos e relatórios de pesquisa em administração. 16.ed. são Paulo: Atlas, 2016. 94p. 